\title{
Mapeamento de riscos na agroindústria familiar e possibilidades de sua mitigação
}

\section{Mapping risks in the family agroindustry and possibilities of its mitigation}

Patrícia Maria Reckziegel da Rocha

patricia_reckziegel@hotmail.com

Mestranda em Administração pela Universidade Estadual do Oeste do Paraná. Bolsista do Programa Bom Negócio Paraná na Universidade Estadual do Oeste do Paraná

Edison Luiz Leismann

elleismann@hotmail.com

Pós Doutorado em Administração (UFPE, 2009), Doutor em Economia Aplicada (UFV 2002). Professor do PPGA-Mestrado Profissional em Administração da UnioesteUniversidade Estadual do Oeste do Paraná. 


\title{
RESUMO
}

$\mathrm{Na}$ agricultura, diversas são as atividades que podem ser desempenhadas pelos agricultores familiares, então neste artigo trataremos sobre as agroindústrias familiares. Este artigo se objetivou a identificar variáveis de riscos nos empreendimentos agroindustriais familiares e avaliar as formas de mitigá-los. Então utilizou-se de pesquisa bibliográfica para identificar na literatura e em sites governamentais quais seriam esses riscos e as formas de mitigá-los. Podemos afirmar que são inúmeros os riscos que sombreiam as agroindústrias familiares, porém apesar de haver riscos para esta atividade, os resultados deste artigo também aponta algumas variáveis que podem ser utilizadas para mitiga-los.

Palavras-chave: Agroindústria Familiar; Agricultura Familiar; Variáveis; Riscos; Mitigação.

\begin{abstract}
This article seeks to describe the extension of actions aimed at sustainable agriculture, carried out by institutions that support farmers in agroecological base. For this, we present a comparative approach involving two groups of farmers of Pernambuco, one connected to an agroecological association, and another formed by setting an official program of agrarian reform. For the survey data, interviews with key sources and with participating farmers of the two experiments were performed. Research shows that, alongside the policies advocated by the governmental sphere in recent years and encouraging the incorporation of Agroecology rural development dynamics, it is essential the support of other actors to overcome the limitations around the different socioeconomic situations, productive, environmental and membership organization present in the strategies and experiences of family farmers.
\end{abstract}

Keywords: Family Farmer; Sustainable Agriculture; Sustainable Rural Development; Settlements; Rural Extension. 


\section{Introdução}

A agricultura familiar não pode ser vista somente pelo prisma econômico, visto que atende a diversos objetivos, dentre os quais, principalmente, os que envolvem aspectos sociais. Neste sentido, Sulzbacher e David (2009) concluem que a agroindústria familiar atinge seus objetivos enquanto promotora da inclusão socioeconômica dos agricultores através da troca de experiências e formação de grupo, assim como pela sociabilidade e geração de renda. Todavia, com o avanço tecnológico da agricultura moderna, as pequenas propriedades enfrentam desafios quanto à sua sustentabilidade econômica. Para Vieira Filho e Ribeiro (2017) a incorporação de tecnologia na agricultura moderna mostra-se crucial para os ganhos de produtividade e para o progresso sustentável. Porém, acompanhar as novas tecnologias, adotando-as, implicam riscos de difícil compreensão e dimensionamento. Por isso, segundo Perez et al. (2009), o surgimento das agroindústrias familiares foi uma alternativa para muitos agricultores que já estavam esgotados com a dinâmica produtiva da modernização.

Não acompanhar as inovações tecnológicas, muitas vezes, significa perda de competitividade visto que os menores custos unitários proporcionados pelas novas tecnologias e pelo efeito escala das unidades econômicas de maior porte, pode comprometer a própria existência da unidade agrícola familiar. Nesta problemática, alguns agricultores incapazes de aderirem às novas tecnologias, são expulsos do mercado, mudando-se para os centros urbanos e para o setor não agrícola (Vieira Filho \& Ribeiro, 2017).

A busca por eficiência das pequenas propriedades num contexto de inovações tecnológicas e mudanças de estruturas de mercado, abriu espaço para a agroindústrias familiares, pois segundo Vieira Filho e Ribeiro (2017, p. 40), “para uma região tornar-se desenvolvida, a economia deveria avançar da produção primária para a fabricação de bens industrializados". Junto com essas oportunidades também surgiram novos riscos que precisam ser mapeados e avaliados em suas possibilidades de mitigação.

Assim, no dia a dia das decisões do agricultor familiar, várias questões relacionadas ao risco e sua possibilidade de mitigação surgem. Essas questões, nem sempre são bem compreendidas, mas tem potencial de impactar na viabilidade econômica e na manutenção das unidades produtivas em ambiente cada vez mais competitivo.

Diversas denominações são usadas para identificar o modelo de agroindustrialização descentralizado, de caráter familiar e de pequeno porte, como 
"pequena agroindústria", "agroindústria familiar", "pequeno estabelecimento de agroindustrialização de alimentos", "agroindústria de pequena escala", "agroindústria caseira" e "agroindústria artesanal", dentre outros conforme Sulzbacher e David (2009), portanto neste trabalho utilizaremos a denominação "agroindústria familiar".

Diante disso, como todo empreendimento corre riscos, este trabalho visa responder ao seguinte questionamento: Quais variáveis de risco impactam na manutenção das agroindústrias familiares e quais as formas para mitigá-los?

\section{Objetivos}

\section{Objetivo geral}

Identificar variáveis de riscos nos empreendimentos agroindustriais familiares e avaliar as formas de mitigá-los.

\section{Objetivos específicos}

a) Avaliar o ambiente econômico dos empreendimentos agroindustriais familiares;

b) Identificar as principais variáveis de risco das empresas agroindustriais familiares;

c) Analisar estratégias e formas de mitigar os riscos dos empreendimentos agroindustriais familiares.

\section{Referencial teórico: agricultura familiar}

A Lei $\mathrm{n}^{\circ}$ 4.504, de 30 de novembro de 1964 que dispõe sobre o Estatuto da Terra, e dá outras providências, no artigo $4^{\circ}$, inciso II, descreve a propriedade familiar como:

O imóvel rural que, direta e pessoalmente explorado pelo agricultor e sua família, lhes absorva toda a força de trabalho, garantindo-lhes a subsistência e o progresso social e econômico, com área máxima fixada para cada região e tipo de exploração, e eventualmente trabalho com a ajuda de terceiros.

A Secretaria Especial de Agricultura Familiar e do Desenvolvimento Agrário (2016) mostra que os dados do Censo Agropecuário de 2006, apontaram que 84,4\% do total dos estabelecimentos agropecuários brasileiros pertencem a grupos familiares, sendo que são aproximadamente 4,4 milhões de estabelecimentos rurais. Ainda de acordo com a Secretaria Especial de Agricultura Familiar e do Desenvolvimento Agrário (2016) a 
agricultura familiar constitui a base econômica de $90 \%$ dos municípios brasileiros com até 20 mil habitantes, responde por 35\% do Produto Interno Bruto - PIB nacional e absorve $40 \%$ da população economicamente ativa do país.

Conforme a Lei $\mathrm{n}^{\mathrm{o}} 11.326$ de 24 de julho de 2016, é considerado agricultor familiar e empreendedor familiar rural aquele que pratica atividades no meio rural, possui área de até quatro módulos fiscais, mão de obra da própria família, renda familiar advinda do próprio estabelecimento e gerenciamento do estabelecimento ou empreendimento pela própria família.

Hamann et al (2010) apontam que o conceito geral de agricultura familiar eram somente as atividades que envolvessem arar solos, plantar sementes, fazer colheitas, ou alimentar animais, porém esse conceito incorporou outros elementos os quais fizeram com que a agricultura pura e simples se tornasse industrializada e empresarial. E para Marchi, Lavorati, Soares, e Godoy (2007, p.108) “a agricultura familiar é a peça fundamental, capaz de estabelecer princípios para o sucesso da construção da proposta de agroindustrialização de pequeno porte de caráter familiar".

\section{Agroindústria familiar}

Segundo Moschen et al. (2011) entendem a agroindustrialização como o beneficiamento dos produtos agropecuários ou a transformação de matérias primas gerando novos produtos, de origem animal ou vegetal e também como uma forma de organização onde a família rural agrega valor ao produto, pois processa e/ou transforma parte de sua produção agrícola e/ou pecuária. No relatório de pesquisa do IPEA (2013, p.56) é relatado que "a agregação de valor é frequentemente considerado o principal mecanismo propulsor de desenvolvimento econômico associado às agroindústrias rurais" e também o IPEA (2013, p.12) aponta que "a transformação de matéria prima de origem agrícola conciliada com a destinação do produto final pelo produtor caracteriza a existência".

Moschen et al. (2011, p.3) novamente citam Prezotto (2002), onde ele afirma que “a pequena agroindústria é uma importante alternativa para promover a participação dos agricultores familiares no processo produtivo, tendo como objetivo atender o consumo da família, como também abastecer o mercado local e regional”. 
Segundo Giraldello et al. (2013), há dois fatores que levaram ao surgimento da agroindústria familiar, o primeiro é de ordem econômica, o qual busca agregar valor aos produtos por meio da sua transformação, e o segundo fator é de ordem social que está associado ao desejo do produtor de permanecer no campo com seus familiares, buscando o envolvimento de todos os membros da família na produção.

O surgimento das agroindústrias familiares está ligado às estratégias sociais e produtivas dos agricultores familiares e demais membros, sejam eles ligados por vínculos de parentescos ou de reciprocidade (Wesz Junior et al. 2006). Cabe destacar que os dados do censo agropecuário Instituto Brasileiro de Geografia e Estatística - IBGE (2007) ressaltaram que $16,7 \%$ dos estabelecimentos rurais no Brasil beneficiaram e/ou transformaram algum tipo de matéria prima. E a partir de seu surgimento, a agroindústria familiar vem sendo considerada como uma importante alternativa de produção para a agricultura de base familiar, porém tem-se a preocupação de que a agroindústria pode trazer uma redução ou a extinção da produção agropecuária nas propriedades (Wesz Junior, 2009). O MDA aponta em suas estimativas que em nível nacional em 2008, existiam aproximadamente 35 mil empreendimentos de agroindustrialização.

A EMATER destaca os objetivos da agroindústria familiar: beneficiar, transformar e ou industrializar a produção; agregar valor aos produtos; melhorar a renda e a qualidade de vida da família rural; profissionalizar o agricultor familiar, inserir e mantê-lo de forma competitiva no mercado; gerar emprego, postos de trabalho e rendas diretas e indiretas; propiciar a comercialização diretamente ao cliente consumidor final; articular as parcerias entre instituições públicas e privadas; fortalecer o processo de organização dos agricultores familiares, dos negócios e de seus empreendimentos.

A EMATER aponta que a agroindústria familiar, faz parte de um cenário de diversificação nas cadeias de suprimentos e que também busca o fortalecimento das ações de fixação e da permanência do homem no campo com as suas atividades agrícolas. A EMATER afirma também que a agroindústria familiar é a base dos negócios da família rural e de grupos de agricultores, em consequência disso vem conquistando espaços da atividade econômica, lucrativa, envolvendo-se cada vez mais com outros setores a exemplo do artesanato rural, turismo tradicional, turismo rural, eco-agro-turismo, lazer, entre outros.

Apesar do grande número de empreendimentos e uma gama de produtos extremamente diversificado no Brasil, o IPEA (2013) afirma que o desenvolvimento da 
agroindústria familiar ainda traz desafios à construção de interpretações consistentes sobre a complexa dinâmica que envolve a circulação e os mercados para os produtos. Assim, o entendimento dos mercados, suas potencialidades e seus gargalos à inserção das agroindústrias rurais é um problema desafiador para as agroindústrias familiares.

Para Hahn et al. (2017) algumas agroindústrias permanecem na clandestinidade devido as dificuldades que encontram, essas dificuldades geralmente estão relacionadas com sua adaptação, pois o processo de aprovação do produto no mercado acaba gerando um desgaste e nesta operação sempre há algo a ser modificado ou melhorado, o que dificulta em termos de recursos, riscos e tempo para o agricultor familiar incorporar as mudanças.

Além de enfrentar os problemas de mercado, as agroindústrias familiares possuem o entrave das instituições e agências reguladoras dos sistemas agroalimentares, pois elas têm operado no sentido de fiscalizar e punir com base nos parâmetros da legislação agroalimentar oficial, seja municipal, estadual ou federal. Essas instituições desconsideram os aspectos culturais que fazem parte da qualidade dos alimentos e centralizam as justificativas apenas nos riscos à segurança alimentar e nutricional dos consumidores, proporcionando ações de abortamento e penalização para os agricultores familiares (Prezotto, 2002 apud IPEA, 2013). Sendo assim, transpor as barreiras da legislação agroalimentar é apenas mais um dos desafios a serem enfrentados pelas agroindústrias familiares.

Ainda sobre o aspecto da dificuldade Caruso e Sacco Anjos (2009) apontam que os agricultores enfrentam uma série de obstáculos, desde financiamentos para a aquisição de equipamentos para a agroindústria, matéria-prima, capital de giro, fluxo de caixa, custos, margem de lucro e impostos e perdem-se com a burocracia. Entretanto, nenhum apoio governamental será plenamente satisfatório sem um ambiente institucional adequado a realidade da agricultura familiar de forma que propicie o sucesso destes empreendimentos rurais.

Sulzbacher e David (2009), afirmam que a escala de produção da agroindústria não pode ultrapassar a capacidade de produção de matéria-prima do grupo doméstico e que, para fins de comercialização, possa atender ao mercado local e, se possível e necessário, regional. Neste sentido, Ellis (2000) apud Gazolla e Pelegrini (2008) apontam que a não produção da matéria-prima é um caminho para o enfraquecimento de sua autonomia, pois a compra da matéria prima de um mercado desconhecido poderá arbitrar 
os preços reais de produção e isso representa uma vulnerabilidade das estratégias de reprodução social das agroindústrias, já que vão depender do mercado, pois de um lado está o preço de produção e de outro, não possuem a garantia de fornecimento, da qualidade da origem da matéria prima comprada para ser processada em seu empreendimento.

Freitas et al. [s.d.] apontam que a formalização da agroindústria valoriza e melhora a qualidade dos produtos, assim possibilitando a ampliação do mercado por meio da comercialização em padarias, mercearias e supermercados locais ou da região, bem como da venda direta ao consumidor. Além disso, proporciona aos produtores a satisfação de trabalhar dentro do mercado formal e aos consumidores a segurança em comprar um produto saudável e de qualidade.

\section{Ambiente econômico da agroindústria familiar}

Nos últimos anos, a agroindústria familiar obteve crescente reconhecimento nos estudos rurais e no âmbito político-institucional em decorrência da importância desta atividade enquanto alternativa econômica aos estabelecimentos rurais (IPEA, 2013).

Segundo Mior (2004) a agroindústria familiar se constitui em um novo espaço e em um novo empreendimento social e econômico, o qual apresenta um conjunto de características que variam de uma região para outra, como exemplo da localização no meio rural, utilização de máquinas e equipamentos e escalas menores, procedência própria da matéria-prima em sua maior parte, processos artesanais próprios, assim como da força de trabalho da família, pode ainda, constituir associações, reunindo uma ou várias famílias, com vínculos de parentesco ou não.

Como já visto, o intuito da agroindústria familiar é agregar valor ao que é produzido na propriedade rural familiar e também uma fonte de renda para os agricultores, porém o IPEA (2013) aponta que a aferição dos custos na agroindústria rural sempre foi uma questão complexa pois não há uma divisão precisa do trabalho, dos insumos e do capital físico entre as diferentes atividades agrícolas, de processamento e não agrícolas. Apesar da dificuldade no cálculo dos custos, a agregação de valor nos produtos eleva a renda das famílias envolvidas e essa remuneração mais elevada torna-se o principal responsável por garantir um diferencial de valor que cobre os custos de implantação do projeto agroindustrial familiar (IPEA, 2013). 
No estudo de Dalbianco et al (2009), onde entrevistaram proprietários de agroindústrias familiares em Santa Rosa - RS, apontam que os entrevistados não possuem condições financeiras suficientes para manter um empregado com carteira assinada e também não conseguem ampliar o negócio para garantir a permanência de seus filhos na atividade das agroindústrias. Neste mesmo estudo os autores afirmam que algumas agroindústrias são administradas por pessoas aposentadas ou com idade mais avançada - no estudo de Hahn et al. (2017) o produtor apresentou uma faixa etária entre 40 e 60 anos - e temem o encerramento da agroindústria devido à falta de pessoas do grupo familiar interessadas em continuar com a atividade, assim, apontam que esta é a realidade de mais de $20 \%$ das agroindústrias onde realizaram o estudo. Os entrevistados deste mesmo estudo ressaltam que os incentivos municipais para a atividade, que possibilite o aumento da renda e a fixação dos jovens para a atividade é a questão central para a reprodução das agroindústrias familiares.

O MDA possui o Programa de Agroindustrialização da Produção da Agricultura Familiar, cujo programa é constituído por duas linhas de crédito, o Pronaf/Agroindústria e Pronaf/Custeio Agroindustrial. O Pronaf/Agroindústria é direcionado como fonte de financiamento para os agricultores interessados na instalação de agroindústrias, nesta linha de crédito são beneficiados os agricultores familiares, como pessoas físicas, cooperativas, associações ou outras pessoas jurídicas constituídas de agricultores familiares, cujo crédito se limita a $\mathrm{R} \$ 18.000,00$ por beneficiário em caso de cooperativas e associações não há limite, porém deve-se observar o limite individual. Já para a linha Pronaf/Custeio Agroindustrial, o público beneficiário é o mesmo do anterior, porém seu uso é para o financiamento das necessidades de custeio do beneficiamento e industrialização e o crédito se limita a $\mathrm{R} \$ 5.000$, individual e $\mathrm{R} \$ 20.000,00$ coletivo ou grupal (Silva \& Prezotto, 2007). Com isso pode-se dizer que os agricultores familiares possuem linhas de crédito que apoiam a agroindustrialização, assim fazendo com que eles tenham a oportunidade de aumento de renda e produtividade.

\section{Risco}

Para Moreira et al. (2010) o risco é o grau de incerteza quanto ao retorno esperado ou a probabilidade de ocorrência de perdas indesejadas, sendo elas financeiras ou não.

Gitman (2004) apud Britto e Rocha (2013, p. 289) veem o risco como: 
O desvio inesperado a partir de um valor médio, ou esperado, atribuído a choques não antecipados e, dessa forma, pode se materializar em perda ou ganho financeiro extraordinário. Sob a ótica dos agentes econômicos, há uma perda de bem-estar sempre que há uma perda financeira e, dessa forma, o termo risco é frequentemente associado à possiblidade de perda.

Ozaki (2007) afirma que em qualquer setor de atividade econômica existem riscos que variam em menor ou maior grau. Portanto no setor agropecuário, além do risco de mercado, existem outros fatores que tornam a atividade arriscada, um dos principais fatores é que a atividade agrícola é completamente dependente das condições climáticas e que está fora do controle do agricultor.

Cenci (2007) em sua dissertação citou que segundo o MDA, a ausência de estudos de viabilidade na implantação; inadequação da escala da agroindústria com o mercado; disponibilidade de matéria prima, mão de obra, capital e equipamentos e instalações; falta de padronização e qualidade; descontinuidade da oferta; baixa capacidade gerencial em todas as etapas do processo produtivo; o baixo nível de organização; pouca disponibilidade de infraestrutura pública; inadequação e desconhecimento das legislações sanitárias, fiscal e tributária e; ausência de suporte creditício para a estruturação produtiva e de capital de giro são os principais fatores de risco que podem determinar o insucesso das agroindústrias familiares.

Para Lourenzani (2006) existem uma série de fatores que afetam significativamente o desempenho dos empreendimentos rurais. Como exemplo, o autor cita que a capacidade de gerenciamento dos produtores rurais, a elaboração de projetos agrícolas para a solicitação de crédito, a tomada de decisão sobre o que produzir, a escolha da tecnologia a ser adquirida, o processo de compra de insumos e venda de produtos, o acesso aos mercados são funções complexas a serem desempenhadas pelos agricultores familiares. Essa deficiência de gestão provoca impactos negativos no desenvolvimento das agroindústrias familiares e em sua integração nos mercados mais dinâmicos. Sendo assim, segundo Lourenzani (2006, p. 314) "não é difícil encontrar produtores familiares em áreas muito desenvolvidas do país, onde exista amplo mercado, disponibilidade de crédito, fornecedores mas com projetos produtivos fracassados.”

Para Santos (2006), embora a agroindústria familiar tenha possibilidade de contribuir com o desenvolvimento da Agricultura Familiar, não se pode negligenciar os riscos e desafios que aos agricultores familiares se depararam ao implantarem um estabelecimento transformador de alimentos com base familiar. Sepulcri (2005) considera 
risco na agricultura a variação não antecipada na produtividade e renda, em função de fatores climáticos e/ou biológicos, riscos associados a variações não antecipadas de preços (mercado), riscos associados a problemas de saúde do trabalhador rural, acidentes, contaminação, dentre outros.

\section{Formas de proteção das agroindústrias}

Segundo Dalbianco et al. (2009) para a manutenção das agroindústrias familiares, elas devem possuir a seu favor condições facilitadas de acesso ao crédito, assistência técnica pública e gratuita, facilidades e distinções com relação as indústrias, bem como devem possuir uma organização coletiva que lhe permita reduzir custos e maximizar a renda.

\section{Seguros}

Como visto anteriormente, a agroindústria se fundamenta na agregação de valor da produção da agricultura familiar, em contrapartida se houver perda da produção a agroindústria será diretamente afetada. Diante desse fator, Ozaki (2007, p. 78) aponta que "o seguro é um dos mecanismos mais eficazes de transferência de riscos e garantia de renda."

\section{Associações}

Um dos instrumentos que vem favorecendo a dinâmica comercial e produtiva das agroindústrias familiares é a organização em cooperativas ou associações. Estes instrumentos de organização permitem ampliar as condições estruturais das agroindústrias familiares, também servem como força de barganha para impulsionar estruturas públicas estatais ou governamentais (Dalbianco et al., 2009).

\section{Assistência técnica}

Silva e Prezotto (2008, p. 5) quando elaboraram a cartilha do Programa de Agroindustrialização da Produção dos Agricultores Familiares, apontaram o objetivo do programa, o qual é "apoiar a agroindustrialização da produção dos agricultores familiares e a sua comercialização, de modo a agregar valor, gerar renda e oportunidades de trabalho no meio rural". Este programa foi desenvolvido pelo Ministério do Desenvolvimento Agrário para a melhoria das condições de vida dos agricultores Familiares. E em relação às legislações o Programa atuou na regulamentação e implantação do Suasa; na 
elaboração, em conjunto com o Ministério do Movimento Agrário, da Resolução do Conama $n^{\circ} 385 / 2006$, que instituiu o processo simplificado para o licenciamento ambiental de pequenas agroindústrias com baixo impacto ambiental (Silva \& Prezotto, 2008).

Considerando as características culturais, a diversidade étnica e o conhecimento dos processos de transformação e conservação de alimentos para o consumo próprio e comercialização do excedente, o EMATER - Instituto Paranaense de Assistência Técnica e Extensão Rural (s.d) elaborou o Projeto Agroindústria Familiar do Paraná - Fábrica do Agricultor, que possui o objetivo de beneficiar, transformar e industrializar a produção, seguindo procedimentos legais e organizar a comercialização, visando melhorar a qualidade de vida das famílias rurais.

Em sua conclusão Wesz Junior (2009) aponta que tanto a assistência técnica como as políticas de incentivo estão atendendo somente os empreendimentos mais consolidados e estruturados, uma pequena parte da realidade da agroindústria familiar, ou seja, não estão contemplando a diversidade e a heterogeneidade dos processos produtivos. Santos (2006), também aponta que os agricultores começam a processar alimentos à margem dos processos legais e a comercializá-los de forma experimental e em alguns casos, essa situação inicial pode continuar, isso ocorre quando os produtos obtidos pelo processamento são pouco significativos em termos de volume e não possuem sustentação econômica para incorporar os custos de investimentos necessários para formalizá-los.

Segundo o estudo de Deponti e Schneider (2007) a extensão rural pública (Secretaria de Desenvolvimento Rural e EMATER) presta assistência técnica por demanda e assim afirmam que

os agricultores que recebem a assistência técnica são aqueles que buscam a diversificação produtiva, sendo também os que apresentam maiores condições financeiras e maior acesso à informação, isso significa que os agricultores com menores condições financeiras, menor visão de mercado e menor acesso à informação são aqueles que também menos recebem assistência técnica (Deponti \& Schneider, 2007, p. 204)

Assim, Deponti e Schneider (2007) inferem que os que os que menos acessam o serviço são os que mais necessitam de assistência técnica. Então podemos dizer que, por falta de informação as famílias com maior vulnerabilidade social, com problemas financeiros e de sobrevivência das famílias são excluídas dos programas. Os autores 
supracitados ainda comentam que apesar dos programas institucionais apresentem recursos financeiros para subsidiar os agricultores, esses recursos não chegam aos mais necessitados justamente pela falta de informação e conhecimento.

\section{Legalização}

Wesz Junior (2009) no resultado de seu estudo, cujo objetivo era visualizar se a agroindústria familiar acaba por fortalecer ou promover a perda de vínculos e semelhanças com a agricultura familiar exclusivamente agrícola, observou que as condições de ilegalidade jurídica e sanitária das agroindústrias têm se apresentado como uma estratégia de manutenção, diversificação e incentivando à produção agropecuária e conforme Niederle e Wesz Junior (2009) a necessidade de cumprir com as exigências jurídicas e sanitárias, traz um problema associado à criação de dependência do Estado, pois as agroindústrias têm desenvolvido uma necessidade crônica de crédito.

Conforme a Federação dos Trabalhadores na Agricultura (FETAG-RS) e a EMATER-RS na cartilha "Agroindústria Familar Rural: Geração de renda e qualiade de vida no meio rural", a agroindústria familiar deve ser legalizada quando a produção não é destinada para o autoconsumo, mas para a comercialização, assim passando a ser de interesse público, das administrações tributárias, sanitária, ambiental e previdenciária, por isso há a necessidade de enquadramento na legislação vigente. E ainda a comercialização só poderá ser feita após o atendimento das normas estabelecidas pela legislação tributária, sanitária e ambiental.

\section{Metodologia}

Para a elaboração deste trabalho utilizou-se a pesquisa bibliográfica que segundo Gil (2008), é desenvolvida com base em material já elaborado, constituído principalmente de livros e artigos científicos e que também podem ser utilizados sites governamentais. Esta pesquisa também tem caráter exploratório que ainda conforme Gil (2008) visa proporcionar maior familiaridade com o problema.

Pesquisou-se em bases bibliográficas, diretamente nas páginas de revistas que tratam sobre os assuntos pertinentes a esta pesquisa e em sites governamentais. A pesquisa foi realizada no mês de junho de 2017 . 


\section{Resultados}

Em face ao objetivo geral deste trabalho que foi identificar variáveis de riscos nos empreendimentos agroindustriais familiares e avaliar as formas de mitigá-los, podemos afirmar através da pesquisa bibliográfica realizada que são inúmeras as variáveis de riscos que sombreiam as agroindústrias familiares, nas quais podemos citar a ilegalidade jurídica e sanitária, falta ou pouca assistência técnica, falta de políticas de incentivo, falta de recursos, baixo volume de produção, alto custo, risco de mercado, falta de matéria prima, falta de conhecimento e gestão, fatores climáticos e biológicos, falta de saúde do agricultor/ acidentes, burocracia, êxodo rural e falta de estrutura física.

Os objetivos específicos deste artigo foram três, dos quais o primeiro visa avaliar o ambiente econômico dos empreendimentos agroindustriais familiares, onde podemos afirmar através da pesquisa realizada que as agroindústrias familiares apesar dos agricultores familiares possuírem incentivos governamentais, como é o caso das linhas de crédito que apoiam a agroindustrialização que fazem com que eles tenham a oportunidade de aumento de renda e produtividade e assistência técnica gratuita, ainda há a dificuldade de reter os jovens no campo para suceder os trabalhos realizados pelos pais, que conforme mostra a pesquisa de Dalbianco et al (2009) que está detalhada no tópico 3.3 deste artigo.

A identificação dos principais fatores de risco das empresas agroindustriais familiares está disposta no segundo objetivo específico, do qual obtivemos a Tabela 1 como resultado.

Tabela 1: Identificação das Variáveis de Risco

\begin{tabular}{l|l}
\hline Variável de Risco & Autor/ano \\
\hline Ilegalidade jurídica e sanitária & Wesz Junior (2009); Santos (2006); Hahn et al. \\
& (2017); Cenci (2007); PREZOTTO, 2002 apud \\
& IPEA (2013) \\
\hline Falta ou pouca assistência técnica & Wesz Junior (2009); Cenci (2007) \\
\hline Falta de políticas de incentivo & Wesz Junior (2009); Niederle \& Wesz Junior \\
& (2009); Dalbianco et al. (2009) \\
\hline Falta de recursos & Niederle \& Wesz Junior (2009); Santos (2006); \\
& Caruso \& Sacco Anjos (2009); Dalbianco et al. \\
& (2009); Cenci (2007) \\
\hline Baixo volume de produção & Santos (2006); Sulzbacher \& David (2009); \\
& Gazolla \& Pelegrini (2008) \\
\hline Alto custo & Santos (2006); Gazolla \& Pelegrini (2008) \\
\hline
\end{tabular}




\begin{tabular}{l|l}
\hline Risco de mercado & $\begin{array}{l}\text { Gazolla \& Pelegrini (2008); Sepulcri (2005); } \\
\text { Hahn } \text { et al. }(2017)\end{array}$ \\
\hline Falta de matéria prima & Gazolla \& Pelegrini (2008); Cenci (2007) \\
\hline Falta de conhecimento/ gestão & IPEA (2013); Cenci (2007); Deponti \& \\
& Schneider (2007) \\
\hline Fatores climáticos e biológicos & Sepulcri (2005); Ozaki (2007) \\
\hline $\begin{array}{l}\text { Falta de saúde do agricultor/ } \\
\text { acidentes }\end{array}$ & Sepulcri (2005) \\
\hline Burocracia & Caruso \& Sacco Anjos (2009) \\
\hline Êxodo rural & Dalbianco et al. (2009) \\
\hline Falta de estrutura física & Cenci (2007) \\
\hline
\end{tabular}

Fonte: Elaborado pelos autores (2017).

Analisar as estratégias e formas de mitigar os riscos dos empreendimentos agroindustriais familiares foi o terceiro objetivo específico, dos quais podemos contar com o seguro agrícola, pois é uma forma de proteção da renda das agroindústrias, pois se houver alguma intempérie do tempo que venha ocasionar a perda da produção de matéria prima para a agroindustrialização, o seguro assegura a renda neste período.

As associações e cooperativas também fazem que a agroindústria familiar se fortaleça, pois segundo Dalbianco et al. (2009) as associações e cooperativas favorecem a dinâmica comercial e produtiva das agroindústrias familiares e também são estes instrumentos de organização que permitem a ampliação das condições estruturais das agroindústrias.

A assistência técnica através de instituições governamentais, é uma oportunidade para a implementação e alavancagem das agroindústrias familiares, pois há programas de subsídios aos que acessam a este tipo de serviço, porém como citam Deponti e Schneider (2007), muitos não acessam e se beneficiam dos programas governamentais por falta de conhecimento.

Outro fator para o sucesso e mitigação dos riscos das agroindústrias familiares é a legalização dos produtos oferecidos ao mercado, pois sem a devida legalização nos órgãos responsáveis a comercialização não é legal, pois segundo a FETAG e a EMATER, como já havíamos mencionado no item 3.5.4, a comercialização só poderá ser feita após o atendimento das normas estabelecidas pela legislação tributária, sanitária e ambiental. 


\section{Considerações finais}

Finalizamos este estudo afirmando que conforme a pesquisa realizada, inúmeros são os riscos que sombreiam as agroindústrias familiares. Porém, se pode observar que a falta de recursos está diretamente ligada à falta de conhecimento e informação dos produtores. A falta de conhecimento também leva o produtor a não buscar assistência técnica gratuita que é oferecida pelos órgãos públicos, fazendo com que não tenham acesso a esse crédito que lhes falta para o aumento da produção, o qual é concedido por meio destas instituições.

Da mesma maneira que necessitam de assistência técnica para o acesso ao crédito, também necessitam dessa assistência para a regularização das agroindústrias dentro das normas legais para que possam comercializar seus produtos.

Outro fator de risco que devemos considerar na agroindústria, é que ela depende da produção da própria matéria prima pelo agricultor familiar proprietário da agroindústria, sendo que o clima é o grande vilão para este risco, esses produtores podem mitigar este risco através do seguro agrícola para que não percam a renda por completo e consigam manter sua agroindústria assim como o sustento de sua família.

Para que as investigações sobre os riscos nas agroindústrias familiares se tornem cada vez mais observados, sugere-se que se façam pesquisas regionalizadas, pois cada estado ou município possui características distintas e também as formas de mitigação em cada um deles pode ser diferente. Assim, com estudos mais regionalizados facilita ao possível empreendedor rural identificar com maior facilidade e exatidão quais os riscos que ele possa vir a ter e a melhor mitigação para os mesmos.

\section{Referências bibliográficas}

Britto, P.A. de; Rocha, C. H. (2013). Implantação de metodologia de minimização de risco : o seguro da agricultura familiar. Revista de Economia e Administração, 12(3), 287-299. https://doi.org/http://dx.doi.org/10.11132/rea.2013.745

Caruso, C. O.; Sacco Anjos, F. (2009). Agroindústrias familiares e sua dificuldade de implementação no extremo sul gaúcho. Sociedade Brasileira de Economia, Administração $e$ Sociologia Rural. Recuperado de http://www.sober.org.br/palestra/13/400.pdf

Cenci, A. (2007). Análise do perfil das agroindústrias familiares situadas na região do Condensus. Programa de Pós Graduação Extenção Rural - UFSM. Recuperado de http://w3.ufsm.br/ppgexr/images/Anásile_das_Agroindústrias_Familiares_da_região_do _CONDESUS.pdf 
Dalbianco, Vinicius Piccin; Botton Piccin, Marcos; Perez, Flávia Carvajal; de Oliveira, N. R. F., Perez, C., Dalbianco, Vinicius Piccin; Botton Piccin, Marcos; Perez, Flávia Carvajal; de Oliveira, N. R. F., Ferndandes, R., \& Oliveira, D. (2009). Limites e potencialidades das agroindústrias familiares: caso do município de Santa Rosa, RS. Sociedade Brasileira de Economia, Administração e $S$ ociologia Rural. Recuperado de http://www.sober.org.br/palestra/13/1082.pdf

Deponti, C. M., \& Schneider, S. (2007). A Extensão Rural e a Diversificação Produtiva da Agricultura Familiar em Áreas de Cultivo de Tabaco no Rio Grande do Sul: o caso de Dom Feliciano-RS. Revista IDeAS Interfaces em Desenvolvimento, Agricultura e Sociedade, 7(2), 176-2013. Recuperado de http://r1.ufrrj.br/cpda/ideas/ojs/index.php/ideas/article/view/141

EMATER - Instituto Paranaense de Assistência Técnica e Extensão Rural. (s.d.). Projeto Agroindústria Familiar do Paraná: Fábrica do Agricultor. Fonte: http://www.emater.pr.gov.br/modules/conteudo/conteudo.php?conteudo=81

FETAG/RS; EMATER/RS; ASCAR ([s.d.]). Agroindústria Familar Rural: Geração de renda e qualiade de vida no meio rural. Cartilha. Recuperado de http://agroindustria.familiar.faccat.br/moodle/pluginfile.php/65/mod_resource/content $/ 2$ /Cartilha_Agroindustria_Familiar_Rural.pdf

Freitas,Jackson Fernandes de; Lima, Marg Margareth de; Silva, Marizete de Oliveira; Ribeiro,Monique Lopes; Dias,Rachel Quandt; Paoli,Talita Maria Pimenta de; Bersani, T. B. ([s.d.]). Agroindústria Familiar - Orientações para a formalização fiscal, ambiental e sanitária. Plano de Desenvolvimento da Agroindústria Familiar e do Empreendedorismo Rural (Agrolegal) GOVERNO DO ESTADO DO ESPÍRITO SANTO . Recuperado de http://agrotures.web2156.uni5.net/Arquivos/Manual - Formalização Agroindústria Agrolegal.pdf

Gazolla, Marcio; Pelegrini, G. (2008). A agroindústria familiar: uma estratégia de agregação de valor a produção e renda das famílias rurais. Apresentação Oral Agricultura Familiar $e$ Ruralidade. Recuperado de http://www.sober.org.br/palestra/13/183.pdf

GIL, Antônio Carlos (2008). Como elaborar projetos de pesquisa. 4. ed. São Paulo: Atlas.

Giraldello, F., Stoffe, J. A., Lima, J. F. de, \& Lavall, V. L. (2013). A agroindústria familiar na microrregião de Francisco Beltrão ( PR ). Rev. FAE, 16(1), 162. Recuperado de https://revistafae.fae.edu/revistafae/article/viewFile/131/76

Hahn, Cláudia Luisa; Casarin, Vanusa Andrea; dos Santos, Antônio Vanderlei; Miranda, Ronaldo Leão de; Ortiz, L. C. V. (2017). Análise de mercado dos produtos da agroindústria familiar: Estudo de caso do perfil do consumidor e do produtor SantoAngelense - Rio Grande do Sul - Brasil Market analysis of the products of the family agroindustry: Case study of the profile of the consu. Revista Espacios, 38(5). Recuperado de http://revistaespacios.com/a17v38n21/a17v38n21p05.pdf

Hamann, Evandro Vieira; Pereira, Ednei Morais; Barreto Junior, Eric Adrian Mattos; Silva, B. F. (2010). Custos para tomada de decisão para agroindústrias familiares da região de Planaltina-DF. XVII Congresso Brasileiro de Custos - Belo Horizonte, MG, 
Brasil.

Recuperado

https://anaiscbc.emnuvens.com.br/anais/article/download/674/674

Instituto de Pesquisa Econômica Aplicada - IPEA. (2013). O Perfil da Agroindústria Rural no Brasil. IPEA - Relatório Técnico. Recuperado de http://www.ipea.gov.br/agencia/images/stories/PDFs/relatoriopesquisa/130319_relatorio _perfil_agroindustria.pdf

Lei $\mathrm{n}^{\circ} 11.326$ de 24 de julho de 2016. ([s.d.]). Recuperado 14 de junho de 2017, de http://www.planalto.gov.br/ccivil_03/_Ato2004-2006/2006/Lei/L11326.htm

Lei $\mathrm{n}^{\mathrm{O}}$ 4.504, de 30 de novembro de 1964. ([s.d.]). Recuperado 13 de junho de 2017, de https://www.planalto.gov.br/ccivil_03/LEIS/L4504.htm

Lourenzani, W. L. (2006). Capacitação gerencial de agricultores familiares: uma proposta metodológica de extensão rural. Organizações Rurais \& Agroindustriais, 8(3), 313-322. Recuperado de http://www.redalyc.org/html/878/87880303/

Marchi, J. F., Lavorati, N., Soares, J. A. Z., \& Godoy, W. I. (2007). Desenvolvimento sócio-econômico das agroindústrias familiares rurai do sudoeste do Paraná. Seminário: Sistemas de Produção Agropecuária - Ciências Agrárias, Animais e Florestais, O(0), 107-109. Recuperado de http://revistas.utfpr.edu.br/dv/index.php/SSPA/article/view/804

Mior, L. C. (2004). Agricultores familiares, agroindústrias e território: a dinâmica das redes de desenvolvimento rural no oeste catarinense. Repositório Institucional da UFSC. Recuperado de https://repositorio.ufsc.br/xmlui/handle/123456789/87731

Moreira, Vilmar Rodirgues; Protil, Roberto Max; Silva, C. L. (2010). Gestão dos Riscos de Mercado do Agronegócio no Contexto das Cooperativas Agroindustriais Agribusines. Sociedade Brasileira de Economia, $48^{\circ}$ Congre. Recuperado de http://www.sober.org.br/palestra/15/919.pdf

Moschen, Fernando; de Oliveira, Lindomar Subtil; Marchi; João Francisco; Adamchuk, D. C. (2011). Características Da Produção Agroindustrial : Um Diagnóstico Do Perfil Sócio-Econômico Das Propriedades Familiares De. Encontro Nacional de Engenharia de Produção. Recuperado http://www.abepro.org.br/biblioteca/enegep2011_TN_STO_141_895_17979.pdf

Niederle, P. A., \& Wesz Junior, V. J. (2009). A agroindústria familiar na região Missões : construção de autonomia e diversificação dos meios de vida. Redes, 14(3), 75-102. Recuperado de http://online.unisc.br/seer/index.php/redes/article/viewFile/566/1431

Ozaki, V. A. (2007). O Papel do Seguro na Gestão do Risco Agrícola e os Empecilhos para o seu Desenvolvimento. Revista Brasileira de Risco e Seguro, 2(4), 75-92. Recuperado de http://www.rbrs.com.br/arquivos/RBRS4-5 Vitor Ozaki On Line.pdf

Perez, Flávia Carvajal; Wizniewsky, José Geraldo; Godoy, Cristiane Maria Tonetto; Moraes, Cléia dos Santos; dos Reys, Marcos Alves. Agroindústrias familiares como estratégia de desenvolvimento para o município de Santa Rosa/RS: O caso da Legislação. (2009) Sociedade Brasileira de Economia, Administração e Sociologia Rural. Recuperado de http://sober.org.br/palestra/13/1066.pdf.

Santos, J. S. (2006). Agroindústria familiar rural no Alto Uruguai do Rio Grande do Sul: uma análise do processo de comercialização, 130. Recuperado de https://repositorio.ufsc.br/handle/123456789/89160 
Secretaria Especial de Agricultura Familiar e do Desenvolvimento Agrário. (2016). O que é a agricultura familiar. Recuperado 13 de junho de 2017, de http://www.mda.gov.br/sitemda/noticias/o-que-é-agricultura-familiar

Sepulcri, O. (2005). Gestão do risco na agricultura. EMATER, 1-11. Recuperado de http://www.emater.pr.gov.br/arquivos/File/Biblioteca_Virtual/Premio_Extensao_Rural/ 2_Premio_ER/18_Gestao_Risco_Agric.pdf

Silva, João Batista da; Prezotto, L. L. (2007). Programa de Agroindustrialização da Produção da Agricultura Familira. Documento Referencial, Edição 2007/2010, 42. Recuperado de http://www.mda.gov.br/sitemda/sites/sitemda/files/user_arquivos_64/01__Documento_Referencial_Agroindústria_versão_site_2007-2010.pdf

Silva, João Batista da; Prezotto, L. L. (2008). Programa de Agroindustrialização da Produção da Agricultura Familiar 2007/2010rio Secretaria da Agricultura Familiar. Cartilha. Recuperado de http://www.mda.gov.br/saf

Sulzbacher, A. W., \& David, C. De. (2009). Agroindústria familiar rural: uma estratégia para melhorar a qualidade de vida no espaço rural. Geosul, 24(47), 69-91. https://doi.org/10.5007/2177-5230.2009v24n47p69

Vieira Filho, José Eustáquio Ribeiro (2017). Agricultura e indústria no Brasil: inovação e competitividade /José Eustáquio Ribeiro Vieira Filho, Albert Fishlow. - Brasília: Ipea. Recuperado http://www.ipea.gov.br/portal/index.php?option=com_content\&id=29768\&Itemid=419.

Wesz Junior, João Valdemar; Trentin, Iran Carlos Lovis; Filippi, E. E. (2006). A importância da agroindustrialização nas estratégias de reprodução das famílias rurais. Sober, 16. Recuperado de http://ageconsearch.umn.edu/bitstream/145990/2/288.pdf

Wesz Junior, V. J. (2009). Agroindústria familiar: um mecanismo de estímulo à especialização das atividades na propriedade rural? Mundo Agrario, 9. Recuperado de http://www.scielo.org.ar/pdf/magr/v9n18/v9n18a02.pdf 